\title{
Educating the Unintended Entrepreneur
}

\author{
Roy Carriker (Drexel University)
}

KEYWORDS: Entrepreneurship, Teaching Methods, student entrepreneurs, Student innovators.

The ranks of "unintended entrepreneurs" are growing, but neither the public nor the universities are fully aware of this yet. These unintended entrepreneurs will come from both the existing workforce of roughly 160 million and the students who will join the workforce in the future. Gathering evidence suggests a growing number of them will be independent self-employed workers -entrepreneurs -- either as a full-time means of earning an income, or part-time to supplement income or to make ends meet. But many are unaware of what the future holds and what it means for their income, and risk being not ready for it. This is a problem for society, but also a tremendous opportunity for education in general and, specifically, for entrepreneurship educators.

Future independent or self-employed workers will be successful only if they are prepared, but it hasn't dawned on many of them that they need to get ready. The public, as well as most schools, still cling to the old paradigm of getting a college degree, taking a related job or career with one or more organizations or companies, and then retiring. They haven't grasped or thought through the concept that entrepreneurial selfemployed independent workers, who may not be able afford retirement, will be the norm in the future.

If independent work will be the major way that people earn a living in the future, it follows that future workers must know how to be the entrepreneurs of their own lives. Business and entrepreneurship schools can show them how, instill a more entrepreneurial mindset, and help them actually earn a living as part-time or full-time self-employed entrepreneurs. However, most of the public has not asked for this type of training because they don't yet realize it is needed, so the schools have focused on training traditional entrepreneurship students who want to start a business. While educators who teach and promote entrepreneurship have much to offer unintended entrepreneurs, they are often limited by the rigid structure of traditional academic institutions. This platform and focus are far too narrow, and it has to change.

\section{FACTORS DRIVING THE US GROWTH OF INDEPENDENT WORKERS}

Much publicly available material shows that middle, lower-middle and low-income workforce members are systematically being devalued or removed from traditional forms of employment because of globalization, robotics, automation, the Internet, and now artificial intelligence. Traditional patterns of career preparation, like going to college, no longer represent a solid path to secure lifetime earnings. The Wall Street Journal and the Federal Reserve Bank of New York reported that $41-46 \%$ of recently polled college graduates responded they did not need their degree to get the job they were able to secure upon graduation. The public is starting to be aware of this, as suggested by a 2017 Colorado law requiring high school counselors to tell students of alternatives to college education such as skilled trades, military careers, etc.

A number of factors are either driving declining economic health of the US workforce or serving as evidence that it's happening. These include a long-term decline in inflation-adjusted wages for middle, lowermiddle and low-income workers and decreasing prospects for students now graduating college. Moreover, many older workers are unable to retire; they are living longer and healthier lives but facing spiraling healthcare costs and a dramatic consolidation of wealth that has limited their ability to save enough for retirement. With the rise of the "gig" economy, with people multitasking to earn a sufficient living, and the growing number of independent or self-employed workers, it's easy to see that the nature of "work" has changed dramatically.

\section{GROWING UNDEREMPLOYMENT}

Unemployment is the benchmark the public generally associates with the economic well-being of the workforce. However, government unemployment figures don't fully capture the true workforce economic stress, 
which is better represented by examining underemployment. When globalization, robotics and automation increased unemployment in US manufacturing, a rising service economy filled the gap. However, in general, service economy employment did not pay as well or carry the same level of fringe benefits as did manufacturing. One could think of these workers as being underemployed with respect to their previous employment. With recent college graduates taking jobs that don't use their college training, this speaks to underemployment, not unemployment, as being a better barometer of workforce economic stress. If the choice is between no job or underemployment that pays less than an individual's skill, training and education might command, one must necessarily opt for underemployment to somehow earn a living.

It is easy to make the case that official US government unemployment figures do not fully capture the economic well-being of the US workforce, primarily due to the US Department of Labor's unemployment sampling methodology for any given period. Beside the narrowness of the sample $(60,000$ households representing roughly 110,000 individuals), persons sampled who have no job and weren't looking for one in the past four weeks are counted as not in the labor force, and thus don't count as unemployed. A possibly even bigger issue with accounting for unemployment in the US is people are considered as employed if they did any work at all for pay or profit during the survey reference week, including all part-time and temporary work. Thus, all those in the gig economy struggling to eke out a living are considered employed, even though they may be closer to unemployment in the traditional sense of earning a living and certainly would qualify as underemployed.

The US still uses rigid historic standards -- either employed or unemployed -- to count numbers in the US workforce. Persons not falling in these two categories are defined as marginally attached to the labor force. To be counted as marginally attached to the labor force, people must indicate they currently want a job, and have looked for work in the past 12 months or since they last worked and are available for work. Discouraged workers are a subset of the marginally attached. Discouraged workers report they are not currently looking for work for one of the following reasons: they believe no job is available to them in their line of work or area; they have previously been unable to find work; they lack the necessary schooling, training, skills or experience; employers think they are too young or too old; or they face some type of discrimination. Marginally attached and discouraged members of the workforce are not counted as being in the workforce and thus do not count as unemployed. All of these factors speak to a significant under-counting of those actually unemployed in the workforce and over-counting those as employed when they are not truly gainfully employed in an historic sense, but rather underemployed.

\section{GROWING INDEPENDENT WORK}

At the moment we are witnessing a reinforcing cycle of disruption in the traditional US labor force with major disruptors being globalization, automation, robotics, leaps in technology and artificial intelligence. This disruption is leading to growth in selfemployment/independent work and is being reinforced by a number of coexisting contributing factors including consolidation of wealth, an aging workforce unable to retire and rising/uncertain healthcare costs. One societal response to this cycle has been the rise of the gig economy with platforms such as Uber, Lyft, Airbnb, TaskRabbit, etc. all aiding workforce members in coping with earning an adequate living.

A 2016 McKinsey Global Institute survey on "independent work" as opposed to those who work in more traditional roles as employees defines four types of independent workers: Free Agents (22 million), Casual Earners (27 million), Reluctants (10 million) and Financially Strapped (9 million). Free agents derive their primary income from independent work and actively prefer it. Casual earners use independent work for supplemental income and do so by choice. Reluctants derive their primary income from independent work but would prefer a traditional job. Finally, financially strapped do independent work for supplemental income to make ends meet but prefer not to do this.

McKinsey groups the first two categories, free agents and casual earners, as independent workers who do so by choice. They group the last two categories, reluctants and financially strapped, as independent workers who do so out of necessity. Of the 54 million to 68 million independent earners (about one third of the US workforce) McKinsey estimates are in the United States, roughly 19 million are in the "out of necessity" category, or something on the order of $13 \%$ of the US workforce. McKinsey's estimated 22 million Free Agents and 10 million Reluctants -- i.e., those deriving their entire income from independent work and not to supplement 
income -- suggests that approximately 32 million are already earning their living as independent contractors in the US. The US Department of Labor put the 2016 US labor force participation at slightly over 150 million, so per McKinsey, nearly $21 \%$ of the US workforce are already earning their living as independent contractors...and their numbers are growing.

US government figures on self-employment show how hard it is to get a clear picture. In April 2014 the Bureau of Labor Statistics put the number of self-employed at roughly 14 million. The US Census Bureau reports data on what they term "non-employer firms," basically companies of one, as being around 24.3 million in 2015, up from 15.4 million in 1997. The Census Bureau economic census data also reported on what they termed one-employee firms. For the years 2002 and 2007 these numbers were 20.9 million and 26.5 million, respectively. In the 2012 census data they stopped reporting this figure.

So it's clear that even government agencies can't agree on just how many of the US workforce are selfemployed, independent workers. Department of Labor and Census Bureau figures don't appear to align and both suggest there are many fewer self-employed in the workforce than the McKinsey study. Some of the lower government estimates are likely due to independent workers not reporting income, While government figures don't tell us as much as McKinsey about the motivation for self-employment, and while different government agencies show different figures, it's still clear that independent work is on the rise.

\section{OTHER CONTRIBUTING FACTORS}

Other factors contribute to unintended entrepreneurship, beyond globalization, robotics and automation, the Internet, disruptive technologies and now artificial intelligence. The historic pattern of working to 65 years of age, retiring, and being replaced by incoming generations has been disrupted. Three interconnected factors are breaking this pattern. In 1950 the average lifespan in the US was 68 years, but now it is 79 years. This means planning for retirement now must cover fourteen years on average rather than just three. At the same time, wealth in the United States has been flowing increasingly into the hands of the already wealthy. This means average citizens are increasingly unable to save enough through their working years to cover their now greatly-extended retirement years. The spiraling and uncertain future costs of healthcare, particularly later in life when healthcare issues increase significantly, add to the problem.

Data from the US Census Bureau civilian labor force participation rate tables show the total number of US employees grew 9\% from 2011 to 2017, to around 153 million. In the same time period, workforce members 55 to 64 years in age grew $18 \%$ to 26.1 million, and for workers 65 and over the growth was $39 \%$ to 9.2 million workers. Thus older members of the workforce are growing at a much greater rate than the workforce in general. Particularly telling is the growth rate of wage earners over 64 years of age is nearly four times that of the total workforce, indicating that older workers are unable to retire at the historic 65 years of age benchmark.

One contributing factor to those 65 and over being unable to retire is the rapid consolidation of wealth in the United States. This decades-long trend has continued for roughly a half century, but now is accelerating. According to studies conducted in 2007 the wealthiest $1 \%$ of Americans owned $34.6 \%$ of the nation's total wealth and the next $19 \%$ of wealthiest households owned $50.5 \%$. Thus in 2007 the wealthiest $20 \%$ of Americans owned $85 \%$ of the nation's wealth, leaving the bottom $80 \%$ of the population owning only $15 \%$ in aggregate. A decade later, in 2017, studies show an alarming acceleration in this wealth consolidation, with the wealthiest $1 \%$ of Americans now owning $40 \%$ of the total wealth in the United States, up from $34.6 \%$ in 2007. As noted previously, in 2007 the wealthiest $20 \%$ of Americans owned $85 \%$ of the nation's total wealth. Now studies indicate the top $20 \%$ of households in the US own $90 \%$ of US wealth, leaving only $10 \%$ of the wealth to be distributed among $80 \%$ of the workforce. As further evidence of workforce economic stress, in recent years households in the bottom $10 \%$ of the US wealth distribution have gone from zero wealth to on average being approximately $\$ 1000$ in debt.

Healthcare costs are adding significantly to workforce economic stress. However, the present state of uncertainty makes quantifying the impact virtually impossible except to note it will be significant in terms of individuals' ability to earn a satisfactory income and consider retirement.

\section{LAUNCHING SOLUTIONS}

It's clear that more current and future employees in the 
workforce are likely to become independent workers. And while society currently has resources to address this issue -- i.e., those involved in entrepreneurship education -- nobody is pushing for it yet because the public has not yet seen the urgency. The challenge is first to create more awareness and then provide vehicles to fill the need.

The second challenge is for entrepreneurship educators to expand their reach. They now are primarily focused on the $0.3 \%$ of all university students having any thought whatsoever about being entrepreneurial. To have the greatest societal impact, they must first break free of the idea that these students are their market, and see that the real market is everyone who will someday need to be entrepreneurial. They must also look beyond the traditional confines of academia and reach out to the unintended entrepreneurs already in the workforce.

So how can entrepreneurship educators and universities involved in entrepreneurship education begin to address better serving a society which will have to be much more entrepreneurial in the future?

For educators themselves:

- Raise awareness of the need for a more entrepreneurial workforce of the future through public forums, seminars, information sessions, etc.

- Don't just sing to the choir by publishing and presenting to your peers. Publish/present informative material in popular public communication vehicles such as newspapers, magazines, online blogs, TED talks, PBS programming, etc. -- all educational platforms that have greater scalability and reach.

- Reach out to high schools and community colleges to promote the reasons entrepreneurship education is necessary to increase the odds of future career success.

- Devote more research to underemployment and different forms of earning a living in the future.

For universities:

- Recognize preparation for earning a living is becoming vastly different than it has been historically. To be "well educated" in the historic sense no longer guarantees earnings potential.

- Recognize being entrepreneurial and having an entrepreneurial mindset is becoming a basic element of potential future success regardless of an individual student's major. In fact, a recent 2 $1 / 2$ year study of 1500 small businesses in Togo, West Africa, indicated elements of entrepreneurship are possibly more important to small enterprise economic success than traditional business training.

- Entrepreneurship educators should recognize that experienced entrepreneurs, not just those with academic skills and credentials, can be great teachers. Experienced non-traditional faculty should be courted and receive the kind of recognition currently biased toward tenure track scholarly academics.

- Engage with and actively support faculty efforts in expanding the understanding of the need for being entrepreneurial, and devise and give recognition to non-traditional forms of entrepreneurship education.....certificates vs. degrees, etc.

- Devise programming that helps faculty from all disciplines in the university to understand how different earning a living in the future will be and the importance of a more entrepreneurial society.

- Create systems and programs that reward faculty members in all disciplines who seek ways to embed a greater entrepreneurial culture across the university.

- Develop educational programming that helps unintended entrepreneurs already in the workforce to earn a living and plan their retirement in a future vastly different from what they have known.

In summary, higher education needs to carefully revisit its role in the preparing the workforce of the future and innovate for outcomes resulting in an economically healthier society. 